\title{
Perbanding Kuat Tekan Paving Menggunakan Bahan Beton Menurut SNI dengan Bahan Campuran Limbah Las Gas
}

\section{Comparison of Compressive Strength of Paving Using Concrete Materials According to SNI with Mixed Materials of Waste Gas Welding}

\author{
Anita Intan Nura Diana ${ }^{1}$, Subaidillah Fansuri ${ }^{1}$ \\ ${ }^{1}$ Jurusan Teknik Sipil, Fakultas Teknik, Universitas Wiraraja Sumenep, Jln. Raya Sumenep-Pamekasan KM. 05 \\ Patean, Panitian Utara, Patean, Batuan, Kabupaten Sumenep, Jawa Timur 69451. Email : anita@wiraraja.ac.id
}

\begin{abstract}
Abstrak
Limbah las gas (karbit) adalah sisa pembakaran karbit yang tidak terpakai. Limbah las gas (karbit) merupakan limbah yang diperoleh dari industri bengkel las karbit. Limbah las gas yang ditimbun dan terbuang tidak didaur ulang akan tidak bermanfaat. Peneliti tertarik untuk meneliti limbah las gas sebagai bahan tambahan pembuatan paving block dengan tujuan menganalisis perbandingan kuat tekan limbah las gas.Penelitian ini menggunakan penelitian percobaan (uji laboratorium). Penelitian menggunakan 4 komposisi campuran limbah las gas dan 1 komposisi control dengan jumlah sampel untuk masing-masing komposisi sebanyak 5 benda uji. pelaksanaan penelitian dilakukan di Laboratorium Teknik Sipil Universitas Wiraraja. Tahapan perbandingan (1PC : 6 PS : 0\% sebagai kontrol; 1PC : 6 PS : 15\%; 1PC: 6 PS : 30\%; 1PC : 6 PS : 45\%; dan 1PC : 6 PS : $60 \%$ ), persiapan alat dan bahan, pembuatan benda uji, pengujian benda uji dan pengolahan data pengujian. Pengujian dilakukan setelah paving block berumur 14 hari.Dari hasil pengujian diperoleh data sebagai berikut: a.) perbandingan selisih rata-rata kuat tekan dari sampel komposisi satu dengan sampel komposisi lainnya, komposisi A dan B sebesar $20.14 \mathrm{~kg} / \mathrm{cm} 2$, komposisi B dan C sebesar $49.71 \mathrm{~kg} / \mathrm{cm} 2$, komposisi C dan D sebesar $29.79 \mathrm{~kg} / \mathrm{cm} 2$, komposisi D dan E sebesar $38.16 \mathrm{~kg} / \mathrm{cm} 2$, komposisi E dan A sebesar $41.34 \mathrm{~kg} / \mathrm{cm} 2 \mathrm{~b}$.) $\mathrm{kuat}$ tekan rata-rata untuk masing-masing komposisi secara berurutan sebesar $127.73 \mathrm{~kg} / \mathrm{cm} 2,135.15 \mathrm{~kg} / \mathrm{cm} 2,84.27$ $\mathrm{kg} / \mathrm{cm} 2,48.76 \mathrm{~kg} / \mathrm{cm} 2$, dan $87.98 \mathrm{~kg} / \mathrm{cm} 2$. Yang memenuhi syarat mutu adalah komposisi A tingkat mutu C sebagai pejalan kaki, komposisi B tingkat mutu C sebagai pejalan kaki, komposisi C tingkat mutu D sebagai taman dan penggunaan lain, komposisi D tingkat mutu D sebagai taman dan penggunaan lain, dan komposisi $E$ tingkat mutu D sebagai taman dan penggunaan lain.
\end{abstract}

Kata Kunci: Kuat Tekan, Paving Block, Limbah Las Gas

\begin{abstract}
Waste gas welding (carbide) is the residual combustion of unused carbide. Waste gas welding (carbide) is a waste obtained from the carbide welding workshop industry. Wastes of waste that are dumped and not recycled will not be useful. The researcher was interested in examining gas welding waste as an additional material for making block paving with the aim of analyzing the comparison of compressive strength of gas welding waste. This study used experimental research (laboratory tests). The study used 4 mixed compositions of gas welding waste and 1 composition control with 5 samples for each composition. the implementation of the research was conducted at the Civil Engineering Laboratory of the University of Wiraraja. Comparison stage (1PC: 6 PS: 0\% as control; 1PC: 6 PS: 15\%; 1PC: 6 PS: 30\%; 1PC: 6 PS: 45\%; and 1PC: 6 PS: 60\%), preparation of tools and materials, making test objects, testing specimens and processing test data. Tests are carried out after the paving block is 14 days. From the test results, the following data are obtained: a) comparison of the average difference in compressive strength from the composition sample one with the other composition samples, composition A and B at $20.14 \mathrm{~kg} / \mathrm{cm} 2$, composition $B$ and $C$ in the amount of $49.71 \mathrm{~kg} / \mathrm{cm} 2$, the composition
\end{abstract}


of $C$ and $D$ is $29.79 \mathrm{~kg} / \mathrm{cm} 2$, the composition of $D$ and $E$ is $38.16 \mathrm{~kg} / \mathrm{cm} 2$, the composition E and A is $41.34 \mathrm{~kg}$ / cm2 b.) The average compressive strength for each composition in sequence amounting to $127.73 \mathrm{~kg} / \mathrm{cm} 2$, $135.15 \mathrm{~kg} / \mathrm{cm} 2,84.27 \mathrm{~kg} / \mathrm{cm} 2,48.76 \mathrm{~kg} / \mathrm{cm} 2$, and $87.98 \mathrm{~kg} / \mathrm{cm} 2$. Those who fulfill the quality requirements are composition $A$ level of quality $C$ as pedestrian, composition $B$ level $C$ quality as pedestrian, composition $C$ level $D$ quality as park and other uses, composition D level D quality as park and other uses, and composition $E$ level quality $D$ as a park and other uses.

Keywords: Press Strength, Paving Block, Welding Gas Waste

\section{PENDAHULUAN}

Limbah las gas (karbit) adalah sisa pembakaran karbit yang tidak terpakai. Limbah las gas (karbit) merupakan limbah yang diperoleh dari industri bengkel las karbit. Umumnya sisa-sisa karbit sisa pengelasan pada besi yang dibuang pada daerah tertentu atau ditimbun di daerah sekitar bengkel las. Salah satu solusi mengatasi limbah yang ada yaitu dengan melakukan daur ulang limbah menjadi paving.

Penelitian yang berjudul Perbandingan Kuat Tekan Paving Menggunakan Bahan Beton Menurut Standar Nasional Indonesia (SNI) Dengan Bahan Campuran Limbah Las Gas ini memberikan alternatif lain. Penulis menawarkan solusi lain dengan menambahkan material baru yaitu limbah las gas yang hasil produksi diharapkan dapat menekan lebih murah biaya produksinya serta meningkatkan kualitas penggunaannya di masa yang akan datang dengan tetap berdasar pada SNI.

\section{Perumusan Masalah}

Berdasarkan latar belakang di atas, maka dapat dirumuskan masalah penelitian sebagai berikut :

Bagaimana hasil kuat tekan pada pembuatan paving menggunakan bahan beton menurut SNI?
Bagaimana hasil kuat tekan pada pembuatan paving menggunakan bahan bahan campuran limbah las gas?

Bagaimana hasil perbandingan kuat tekan paving menggunakan bahan beton menurut SNI dengan bahan campuran limbah las gas?

\section{Tujuan dan Manfaat}

Adapun tujuan dan manfaat dari penelitian ini adalah sebagai berikut :

Mengetahui kuat tekan pada pembuatan paving menggunakan bahan beton menurut SNI.

Mengetahui kuat tekan pada pembuatan paving menggunakan bahan bahan campuran limbah las gas.

Mengetahui perbandingan kuat tekan paving menggunakan bahan beton menurut SNI dengan bahan campuran limbah las gas.

Memberikan informasi seberapa besar kuat tekan paving dengan menggunakan bahan campuran limbah las gas.

Memberikan wawasan pembuatan paving dengan penambahan limbah las gas.

\section{METODE}

Penelitian Paving block menggunakan tahapantahapan penelitian yaitu persiapan alat dan bahan uji, pengujian bahan paving block (pengujian berat Proteksi/Desember 2019 Volume 1 No. 2 
jenis dan penyerapan air,pengujian ayakan agregat, dan kadar air), pembuatan paving block (dengan masing-masing komposisi kelompok adalah kelompok I 1pc : 6ps : 01lg, kelompok II 1pc : 6ps : 0,91lg, kelompok III 1pc : 6ps : 1,81lg, kelompok IV 1pc : 6ps : 2,7llg, dan kelompok V $1 \mathrm{pc}: 6 \mathrm{ps}: 3,61 \mathrm{lg}$, pengeringan paving block, pengujian paving block (pengujian kuat tekan). Hasil penelitian dibandingkan dengan standar SNI paving block telah memenuhi atau tidak memenuhi standar SNI.

\section{HASIL DAN PEMBAHASAN}

\section{Hasil Pemeriksaan Bahan Paving Block}

\section{Air}

Air merupakan bahan campuran pembuatan paving block, dimana air dilakukan pemeriksaan dengan pengamatan secara visual.

\section{Semen}

Semen yang akan dicampurkan ke dalam pembuatan paving block dilakukan pemeriksaan dengan memperhatikan kemasan semen dan tekstur dari butiran-butiran semen. Hasil pemeriksaan tersebut,

\section{Pasir Hitam}

a. Pengujian Berat Jenis, Penyerapan Air dan Kadar Air

Hasil pengujian untuk berat jenis dari pasir hitam adalah yaitu 2,17, dan untuk berat jenis pasir jenuh (JPK/SSD) yaitu 2,54 dan berat jenis semu (apparent) sebesar 3,44. Menghasilkan penyerapan air untuk pasir hitam yaitu 16,95\% dan kadar air pasir hitam yaitu $7,93 \%$.

\section{b. Pengujian Analisa Ayak}

Pengujian Hasil pengujian analisa ayak pasir hitam mempunyai gradasi yang mendekati daerah 2 seperti yang terlihat pada gambar

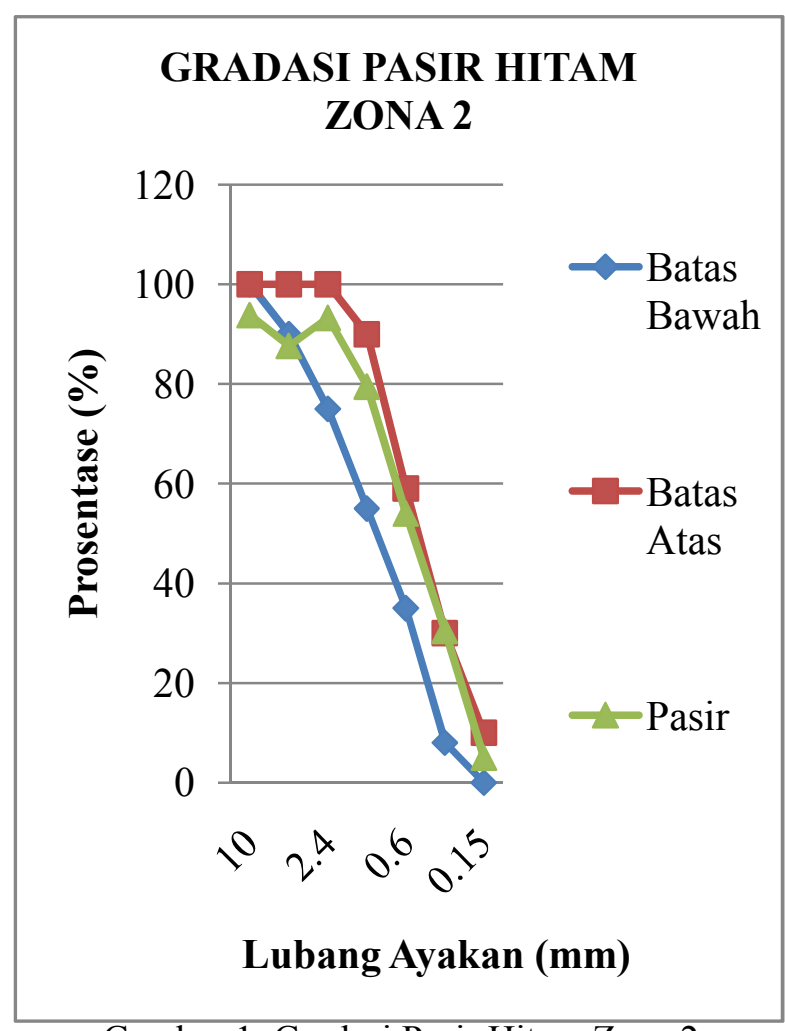

Gambar 1. Gradasi Pasir Hitam Zona 2

\section{Limbah Las Gas}

Pengujian Analisa Ayak

Hasil pengujian analisa ayak limbah las gasmempunyai gradasi yang mendekati daerah 1 seperti yang terlihat pada gambar 


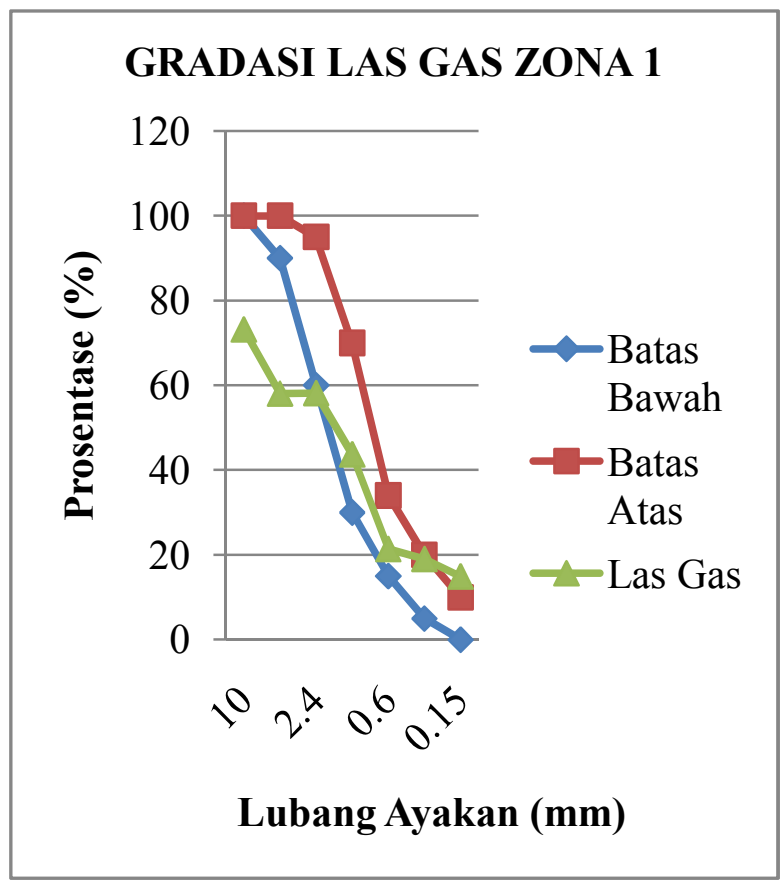

Gambar 2. Gradasi Las Gas Zona 1

\section{Paving Block}

\section{Pengujian Kuat Tekan}

Pengujian kuat tekan dilakukan disesuaikan dengan standar SNI 03 - 1968 - 1990. Hasil pengujian kuat tekan pada penelitian ini mengalami penurunan.

Percobaan paving kelompok I (limbah las gas 0\%) sampel 1 dengan berat 2070.8 gram menghasilkan tegangan hancur (kuat tekan) sebesar 159.00 $\mathrm{kg} / \mathrm{cm} 2$; sampel 2 dengan berat 2121.8 gram menghasilkan tegangan hancur (kuat tekan) sebesar $121.90 \mathrm{~kg} / \mathrm{cm} 2$; sampel 3 dengan berat 2102.7 gram menghasilkan tegangan hancur (kuat tekan) sebesar $132.50 \mathrm{~kg} / \mathrm{cm} 2$; sampel 4 dengan berat 2057.0 gram menghasilkan tegangan hancur (kuat tekan) sebesar $145.75 \mathrm{~kg} / \mathrm{cm} 2$; sampel 5 dengan berat 1982.4 gram menghasilkan tegangan hancur (kuat tekan) sebesar $113.95 \mathrm{~kg} / \mathrm{cm} 2$.
Percobaan paving kelompok II (limbah las gas 15\%) sampel 1 dengan berat 2088.4 gram menghasilkan tegangan hancur (kuat tekan) sebesar $121.90 \mathrm{~kg} / \mathrm{cm} 2$; sampel 2 dengan berat 2038.7 gram menghasilkan tegangan hancur (kuat tekan) sebesar $143.10 \mathrm{~kg} / \mathrm{cm} 2$; sampel 3 dengan berat 2040.2 gram menghasilkan tegangan hancur (kuat tekan) sebesar $135.15 \mathrm{~kg} / \mathrm{cm} 2$; sampel 4 dengan berat 2076.8 gram menghasilkan tegangan hancur (kuat tekan) sebesar $119.25 \mathrm{~kg} / \mathrm{cm} 2$; sampel 5 dengan berat 2053.4 gram menghasilkan tegangan hancur (kuat tekan) sebesar $127.2 \mathrm{~kg} / \mathrm{cm} 2$.

Percobaan paving kelompok III (limbah las gas $30 \%$ ) sampel 1 dengan berat 1872.6 gram menghasilkan tegangan hancur (kuat tekan) sebesar $84.80 \mathrm{~kg} / \mathrm{cm} 2$; sampel 2 dengan berat 1822.0 gram menghasilkan tegangan hancur (kuat tekan) sebesar $82.15 \mathrm{~kg} / \mathrm{cm} 2$; sampel 3 dengan berat 1823.2 gram menghasilkan tegangan hancur (kuat tekan) sebesar $66.25 \mathrm{~kg} / \mathrm{cm} 2$; sampel 4 dengan berat 1857.3 gram menghasilkan tegangan hancur (kuat tekan) sebesar $84.80 \mathrm{~kg} / \mathrm{cm} 2$; sampel 5 dengan berat 1846.1 gram menghasilkan tegangan hancur (kuat tekan) sebesar $82.15 \mathrm{~kg} / \mathrm{cm} 2$.

Percobaan paving kelompok IV (limbah las gas $30 \%$ ) sampel 1 dengan berat 1850.7 gram menghasilkan tegangan hancur (kuat tekan) sebesar $60.95 \mathrm{~kg} / \mathrm{cm} 2$; sampel 2 dengan berat 1757.0 gram menghasilkan tegangan hancur (kuat tekan) sebesar $31.80 \mathrm{~kg} / \mathrm{cm} 2$; sampel 3 dengan berat 1770.8 gram menghasilkan tegangan hancur (kuat tekan) sebesar $50.35 \mathrm{~kg} / \mathrm{cm} 2$; sampel 4 dengan berat 1838.1 gram menghasilkan tegangan hancur (kuat tekan) sebesar $58.30 \mathrm{~kg} / \mathrm{cm} 2$; sampel 5 dengan berat 1769.6 gram menghasilkan tegangan hancur (kuat tekan) sebesar 
$47.70 \mathrm{~kg} / \mathrm{cm} 2$. Kuat tekan paving dengan campuran limbah las gas $45 \%$ rata-rata sebesar $48.76 \mathrm{~kg} / \mathrm{cm} 2$.

Percobaan paving kelompok V (limbah las gas 60\%) sampel 1 dengan berat 1815.1 gram menghasilkan tegangan hancur (kuat tekan) sebesar $100.70 \mathrm{~kg} / \mathrm{cm} 2$; sampel 2 dengan berat 1874.6 gram menghasilkan tegangan hancur (kuat tekan) sebesar $90.10 \mathrm{~kg} / \mathrm{cm} 2$; sampel 3 dengan berat 1793.2 gram menghasilkan tegangan hancur (kuat tekan) sebesar $82.15 \mathrm{~kg} / \mathrm{cm} 2$; sampel 4 dengan berat 1790.0 gram menghasilkan tegangan hancur (kuat tekan) sebesar $79.50 \mathrm{~kg} / \mathrm{cm} 2$; sampel 5 dengan berat 1826.3 gram menghasilkan tegangan hancur (kuat tekan) sebesar $87.45 \mathrm{~kg} / \mathrm{cm} 2$.

Kuat tekan paving dengan campuran limbah las gas $60 \%$ rata-rata sebesar $87.98 \mathrm{~kg} / \mathrm{cm} 2$. Dari 4 komposisi campuran paving, nilai kuat tekan yang mendekati hasil SNI adalah paving dengan campuran limbah las gas 15\%.

\section{KESIMPULAN}

Hasil pengujian dari berat jenis untuk pasir hitam adalah yaitu 2,17 , berat jenis (JPK/SSD) yaitu2,54 dan berat jenis apparent yaitu 3,44. Menghasilkan penyerapan air untuk pasir hitam yaitu $16,95 \%$ dan kadar air yaitu 7,93\%.

Kuat tekan paving dengan campuran limbah las gas $60 \%$ rata-rata sebesar $87.98 \mathrm{~kg} / \mathrm{cm} 2$. Dari 4 komposisi campuran paving, nilai kuat tekan yang mendekati hasil SNI adalah paving dengan campuran limbah las gas 15\%.
Berdasarkan dari pengujian paving dengan penambahan limbah las gas sebesar $0 \%, 15 \%, 30 \%$, $45 \%$ dan $60 \%$ dari berat pasir tanpa mengurangi pasir pada 5 (lima) jenis komposisi atau campuran yang dicoba, dapat diambil kesimpulan sebagai berikut :

\section{Pengujian kuat tekan}

Pengujian kuat tekan pada paving block dengan campuran $0 \%$ hasil kuat tekan sebesar 127.73 $\mathrm{kg} / \mathrm{cm} 2$.

Hasil pengujian kuat tekan pada paving block dengan campuran tambahan limbah las gas 15\% sebesar $135.15 \mathrm{~kg} / \mathrm{cm} 2,30 \%$ sebesar $84.27 \mathrm{~kg} / \mathrm{cm} 2$, $45 \%$ sebesar $48.76 \mathrm{~kg} / \mathrm{cm} 2,60 \%$ sebesar 87.98 $\mathrm{kg} / \mathrm{cm} 2$.

Perbandingan kuat tekan paving block menurut SNI dengan campuran limbah las gas maka dari beberapa komposisi yang kuat tekannya mengalami kenaikan adalah limbah las gas $15 \%$.

Mutu Paving Block Berdasarkan SNI (Standat Nasional Indonesia)

Menurut SNI 03-0691-1996 Mutu D dengan kuat tekan rata-rata sebesar $10 \mathrm{MPa}$ dengan Min. 8.5 MPa, sedangkan penelitian limbah las gas mempunyai rata-rata kuat tekan sebesar 9.60 MPa. Jadi paving block limbah las 


\section{REFERENSI}

Badan Standarisasi Nasional, 1996, Bata Beton (Paving Block) (SNI 03 - 0691 - 1996), Standar Nasional Indonesia.

Buku Petunjuk Praktikum Teknologi Beton dan Bahan, Laboratorium Beton dan Bahan Bangunan Teknik Sipil. Institut Teknologi Surabaya (ITS).

Buku Petunjuk Praktikum Transportasi dan Jalan Raya, Laboratorium Transportasi dan Jalan Raya. Universitas Brawijaya Malang (UB).

Murdock. L. J, K.M. Brook, Ir. Stephanus Hindarko, 1999, Bahan dan Praktek Beton Edisi Keempat, Jakarta, Penerbit Erlangga.

Nugraha Paul, Antoni, 2004, Teknologi Beton Dari Material Pembuatan ke Beton Kinerja Tinggi, Yogyakarta, Penerbit ANDI. 